\title{
Regional differences in hepatitis $C$ treatment with peginterferon and ribavirin in Japan: a retrospective cohort study
}

This article was published in the following Dove Press journal:

Drug Design, Development and Therapy

22 March 2016

Number of times this article has been viewed

\section{Kazuki Ide' \\ Yohei Kawasaki' \\ Hiroshi Yamada' \\ Naohiko Masaki² \\ 'Department of Drug Evaluation and Informatics, Graduate School of Pharmaceutical Sciences, University of Shizuoka, Shizuoka, ${ }^{2}$ The Research Center for Hepatitis and Immunology, National Center for Global Health and Medicine, Chiba, Japan}

Purpose: The aims of this study were to investigate regional differences in hepatitis $\mathrm{C}$ virus $(\mathrm{HCV})$ infection treatment with peginterferon and ribavirin in Japan and to develop and validate statistical models for analysis of regional differences, using generalized linear mixed models. Methods: Individuals with chronic HCV infection were identified from the Japanese Interferon Database (registered from December 2009 to April 2013). The total sustained virologic response rate and the rate in each prefecture were calculated. In the analysis using generalized linear mixed models, the following four models were constructed: 1) prefecture as a fixed effect, 2) prefecture and other confounding variables as fixed effects, 3) prefecture as a random effect, and 4) prefecture as a random effect and other confounding variables as fixed effects. The quality of the model fit was assessed using the Akaike information criterion and the Bayesian information criterion. All statistical analyses were performed using SAS Version 9.4 for Windows.

Results: From 36 prefectures, 16,349 cases were recorded in the study period. Of these, 4,677 were excluded according to certain criteria. The total sustained virologic response rate was $59.9 \%$ (range, $43.9 \%-71.6 \%$ ). The statistical model including prefecture as a random effect and other confounding variables as fixed effects showed the best fit based on the Akaike information criterion $(13,830.92)$ and Bayesian information criterion $(13,845.17)$.

Conclusion: Regional differences may exist in HCV infection treatment in Japan. The model including prefecture as a random effect and other confounding variables as fixed effects was appropriate for analysis of such regional differences. Additional studies considering the medical situations of each patient would provide useful information that could contribute to improve and standardize HCV infection treatment.

Keywords: hepatitis C virus, interferon, regional differences, nationwide database, generalized linear mixed model

\section{Introduction}

Hepatitis $\mathrm{C}$ is a liver infection caused by hepatitis $\mathrm{C}$ virus (HCV). HCV can cause both acute and chronic infections. Although acute HCV infection is typically asymptomatic or mild, $55 \%-85 \%$ of individuals with HCV will develop chronic infection, which is a leading cause of cirrhosis. ${ }^{1,2}$ Globally, 130-150 million individuals have chronic $\mathrm{HCV}$ infection, and $>300,000$ individuals die from HCV-related liver disease annually. ${ }^{2,3}$ Antiviral treatment with peginterferon (PEG-IFN) and ribavirin (RBV) is a common approach for $\mathrm{HCV}$ infection. ${ }^{4}$ Interferon (IFN)-free approaches using direct-acting antiviral agents have also been developed in recent years and have shown an improved sustained virologic response (SVR) rate of $>90 \%$ in Phase II and III clinical trials..$^{5-7}$ However, treatment with PEG-IFN and RBV is still commonly used
Correspondence: Yohei Kawasaki Department of Drug Evaluation and Informatics, Graduate School of Pharmaceutical Sciences, University of Shizuoka, 52-I Yada, Suruga-ku, Shizuoka 422-8526, Japan Tel/fax +8I 54264559 I

Email ykawasaki@u-shizuoka-ken.ac.jp
Drug Design, Development and Therapy 2016:10 1217-1223

1217

Dovepress

http://dx.doi.org/1 0.2147/DDDT.S102458 (c) (1) (5) 2016 Ide et al. This work is published and licensed by Dove Medical Press Limited. The full terms of this license are available at https://www.dovepress.com/terms.php
and incorporate the Creative Commons Attribution - Non Commercial (unported, v3.0) License (http://creativecommons.org/licenses/by-nc/3.0/). By accessing the work you

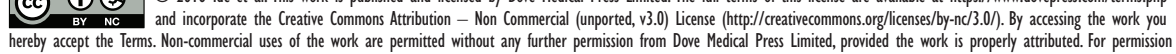
for commercial use of this work, please see paragraphs 4.2 and 5 of our Terms (https://www.dovepress.com/terms.php). 
due to the exceptionally high cost of new treatments ${ }^{8}$ and limited revision of treatment guidelines for $\mathrm{HCV}$ infection. ${ }^{4}$ In clinical practice, standardization of treatment performance and outcomes of antiviral therapy is essential to control the $\mathrm{HCV}$ epidemic and to reduce the occurrence of liver disease associated with HCV infection, such as cirrhosis and hepatocellular carcinoma. ${ }^{9}$ Focusing on chronic HCV infection treatment in Japan, in 2015, Masaki et $\mathrm{al}^{10}$ reported regional differences in IFN treatment. Their study showed regional disparities in IFN treatment in nine regions from north to south Japan. However, their study did not investigate differences among prefectures - the unit of local government in Japan - and also did not consider the appropriate statistical models for analysis of regional differences.

Therefore, in this study, we investigated regional, particularly prefectural, differences in $\mathrm{HCV}$ infection treatment with PEG-IFN and RBV in Japan using the Japanese Interferon Database. The appropriate statistical model for analysis of regional differences was also evaluated using generalized linear mixed models (GLMMs).

\section{Methods}

\section{Study design}

The Japanese Interferon Database was constructed from a nationwide retrospective cohort study beginning in December 2009, which was authorized by the Basic Act on Hepatitis Measures (Act No 97; December 4, 2009). All 47 prefectural governments in Japan were invited to participate in the study. Those prefectures that agreed to participate sent their data to the Hepatitis Information Center (Chiba, Japan) using a standardized case report form that included demographic features of the individuals (sex, date of birth, age, and IFN treatment history), clinical and/or histologic diagnosis, scheduled treatment data, IFN treatment regimen (type of IFN and with or without RVB), laboratory test results (serum HCV RNA level, HCV serotype and/or genotype, aspartate aminotransferase level, alanine aminotransferase [ALT] level, and platelet count), adverse events, and treatment outcomes (SVR and complement of treatment). Serum HCV RNA level was measured using quantitative real-time polymerase chain reaction (COBAS Ampliprep/COBAS TaqMan HCV test; F. Hoffmann-La Roche Ltd, Basel, Switzerland). Written informed consent was obtained from all participants prior to enrollment. The study protocol was approved by the Ethics Committee of the National Center for Global Health and Medicine of Japan (No 738; October 1, 2009) and was conducted in accordance with the Declaration of Helsinki.

\section{Study population}

Individuals with chronic $\mathrm{HCV}$ infection were identified from the Japanese Interferon Database (registered from December 2009 to April 2013). Individuals who met any of the following criteria were excluded: comorbid cirrhosis or hepatitis $B$ virus infection, treatment other than PEG-IFN and RBV, younger than 16 years (prognosis of the disease in children is different from that in adults ${ }^{11}$ ), and missing data (age, sex, diagnosis, treatment, or other clinical data).

\section{Treatment outcomes}

The virologic response of individuals was assessed by each doctor in the participating prefecture based on the following standard criteria: SVR was defined as reduction in serum HCV RNA to less than detectable levels at 24 weeks after cessation of treatment; transient virologic response was defined as reappearance of serum HCV RNA after cessation of treatment following a transient undetectable state during treatment; nonvirologic response was defined as a $<2 \log$-unit decline in serum HCV RNA from baseline within the first 12 weeks and at 24 weeks after starting treatment.

\section{Statistical analysis}

Continuous variables were expressed as mean $\pm \mathrm{SD}$, while categorical variables were expressed as number and percentage. The SVR rate in each prefecture was calculated based on case reports from the local government. Confounding variables were explored by using stepwise multivariate logistic regression analysis. The stepwise selection process comprised alternating forward selection and backward elimination. The significance level of selection and elimination was set at 0.15 . In multivariate logistic regression analysis, adjusted odds ratios (OR)s and 95\% confidence interval (CI)s were calculated. The fit of the logistic regression model was assessed using the Hosmer-Lemeshow test. ${ }^{12}$ Confounding variables selected from stepwise multivariate logistic regression analysis were transferred to the analysis using GLMMs. ${ }^{13}$ In the GLMMs, let $\left(Y_{i}\right)_{i=1, \ldots, N}$ be Bernoulli variables with probability distribution

$$
P\left(Y_{i}=1 \mid \eta_{i}\right)=\frac{\exp \left(\eta_{i}\right)}{1+\exp \left(\eta_{i}\right)}, \eta_{i}=\boldsymbol{x}_{i} \boldsymbol{\beta}+z_{i} \boldsymbol{u}
$$

in which $\beta$ is the fixed-effect parameter; $\boldsymbol{x}_{i}$ is the $i$ th row of the $N \times p$ design matrix $\boldsymbol{X}$ for the fixed effect; $\boldsymbol{u}$ is the random-effect parameter, which has normal distribution with a mean of 0 and variance matrix $\sum$; and $z_{i}$ is the $i$ th row of the $N \times r$ design matrix $\boldsymbol{Z}$ for the random effect. We calculated 
point estimates of $\boldsymbol{\beta}$ and $\boldsymbol{u}$. Their upper and lower limits were also estimated. In this study, the following four models were constructed to determine the appropriate model for analysis of regional differences: 1) prefecture as a fixed effect, 2) prefecture and other confounding variables as fixed effects, 3) prefecture as a random effect, and 4) prefecture as a random effect and other confounding variables as fixed effects. The quality of the model fit was assessed using the Akaike information criterion (AIC) ${ }^{14}$ and the Bayesian information criterion (BIC). ${ }^{15}$ All statistical analyses were performed using SAS Version 9.4 for Windows (SAS Institute Inc., Cary, NC, USA).

\section{Results}

Among 36 out of 47 prefectures in Japan, 16,349 cases of chronic HCV infection were recorded in the Japanese Interferon Database from December 2009 to April 2013. Of these, 4,677 individuals were excluded according to the exclusion criteria: 56 had age and/or sex data missing, four were younger than 16 years, 300 had hepatitis B virus infection, 569 had cirrhosis, 163 had diagnostic data missing, 2,892 received treatment other than PEG-IFN and RBV, and 735 had other clinical data missing. Several individuals had more than one reason for exclusion. Therefore, a total of 11,672 individuals with chronic HCV infection were included in the analysis. The characteristics of these individuals are reported in Table 1 . The mean age was $57.9 \pm 10.5$ years; $5,896(50.5 \%)$

Table I Clinical characteristics

\begin{tabular}{|c|c|}
\hline Clinical characteristic & \\
\hline $\bar{N}$ & 11,672 \\
\hline Age, mean $\pm S D$, years & $57.9 \pm 10.5$ \\
\hline \multicolumn{2}{|l|}{ Sex, n (\%) } \\
\hline Male & $5,896(50.5)$ \\
\hline Female & $5,776(49.5)$ \\
\hline \multicolumn{2}{|l|}{ Genotype, n (\%) } \\
\hline I & $7,950(68.1)$ \\
\hline 2 & $3,703(31.7)$ \\
\hline 3 & $19(0.2)$ \\
\hline \multicolumn{2}{|l|}{ Platelet count, n (\%) } \\
\hline$\leq 15 \times 10^{4} / \mu \mathrm{L}$ & $4,705(40.3)$ \\
\hline$>15 \times 10^{4} / \mu \mathrm{L}$ & $6,967(59.7)$ \\
\hline \multicolumn{2}{|l|}{ ALT level, n (\%) } \\
\hline$>30 \mathrm{IU} / \mathrm{L}$ & $9,118(78.1)$ \\
\hline$\leq 30 \mathrm{IU} / \mathrm{L}$ & $2,554(21.9)$ \\
\hline \multicolumn{2}{|l|}{ HCV viral load, $n(\%)$} \\
\hline High & $10,903(93.4)$ \\
\hline Low & $769(6.6)$ \\
\hline \multicolumn{2}{|c|}{ Treatment experience, $n$ (\%) } \\
\hline Initial treatment & $8,628(73.9)$ \\
\hline Retreatment & $3,044(26.1)$ \\
\hline
\end{tabular}

Abbreviations: $A L T$, alanine aminotransferase; $H C V$, hepatitis $C$ virus. were men and 5,776 (49.5\%) were women; 7,950 (68.1\%) had HCV genotype 1, 3,703 (31.7\%) had HCV genotype 2, and $19(0.2 \%)$ had HCV genotype 3; and 8,628 (73.9\%) were undergoing initial treatment.

\section{SVR rate in each prefecture}

The total SVR rate and the rate in each prefecture were calculated based on case reports from the local government (Figure 1 and Table 2). The total SVR rate was 59.9\% $(6,989 / 11,672)$, with a range from $43.9 \%$ (prefecture No 31 ) to $71.6 \%$ (prefecture No 36 ). The number of cases registered in the 36 prefectures ranged from 12 to 1,391 . Seven out of 36 prefectures registered $<100$ cases.

\section{Multivariate logistic regression analysis}

In stepwise multivariate logistic regression analysis, age (adjusted OR, 0.964; 95\% CI, 0.959-0.968; $P<0.0001$ ), sex (adjusted OR, 1.376; 95\% CI, 1.267-1.494; $P<0.0001$ ), platelet count (adjusted OR, 1.505; 95\% CI, 1.385-1.636; $P<0.0001$ ), ALT level (adjusted OR, 1.194; 95\% CI, 1.079-1.320; $P=0.0006$ ), HCV viral load (adjusted OR, $0.321 ; 95 \%$ CI, 0.263-0.392; $P<0.0001$ ), genotype (adjusted OR, 3.847; 95\% CI, 3.491-4.239; $P<0.0001$ ), and treatment experience (adjusted OR, 0.691; 95\% CI, 0.631-0.756; $P<0.0001$ ) were selected as confounding variables (Table 3 ). This multivariate logistic model showed a good fit (HosmerLemeshow test, $P=0.9125$ ), and these confounding variables were considered in the analysis using GLMMs.

\section{GLMMs for analysis of regional differences}

The quality of the model fit is shown in Figure 2. The AIC and BIC of the models were as follows: 1) prefecture as a fixed effect, $\mathrm{AIC}=15,721.68$ and $\mathrm{BIC}=15,986.82 ; 2$ ) prefecture and other confounding variables as fixed effects, $\mathrm{AIC}=13,845.30$ and $\mathrm{BIC}=14,161.99 ; 3)$ prefecture as a random effect, $\mathrm{AIC}=15,716.27$ and $\mathrm{BIC}=15,719.43$; and 4) prefecture as a random effect and other confounding variables as fixed effects, $\mathrm{AIC}=13,830.92$ and $\mathrm{BIC}=13,845.17$.

\section{Discussion}

This study was conducted to investigate regional differences in HCV infection treatment with PEG-IFN and RBV in Japan using a nationwide database. The appropriate statistical model for analysis of such regional differences was also evaluated.

The SVR rates of 36 prefectures in Japan ranged from $43.9 \%$ to $71.6 \%$, indicating that regional differences in $\mathrm{HCV}$ infection treatment with PEG-IFN and RBV may exist, and 


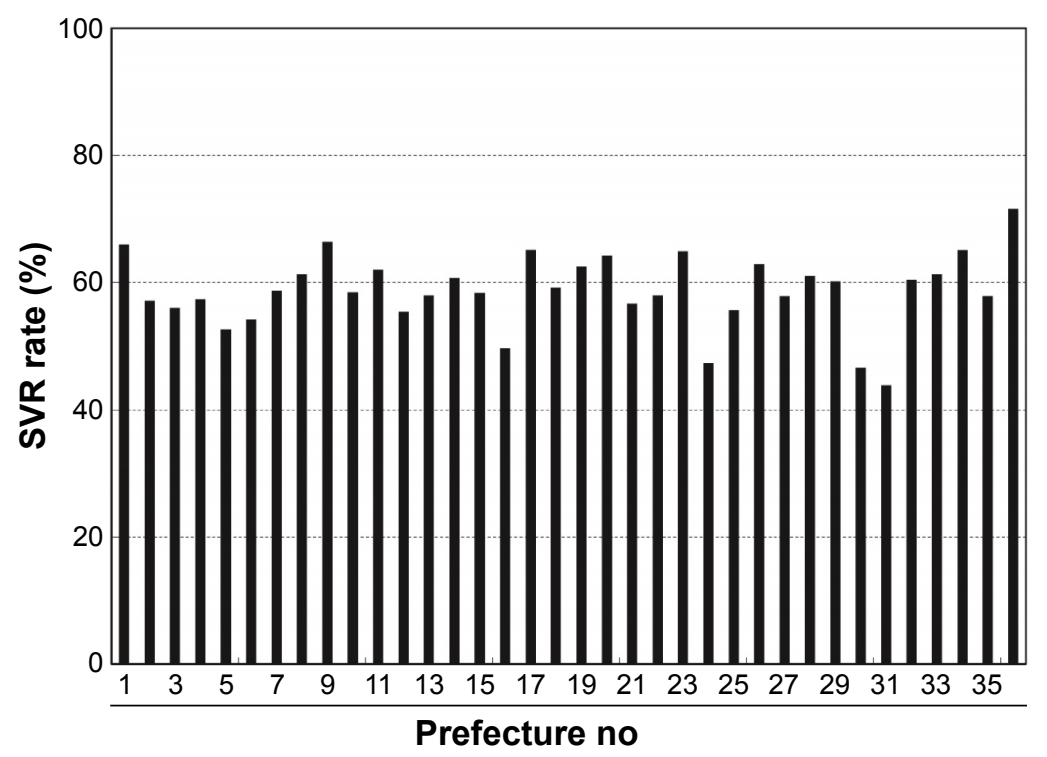

Figure I Distribution of sustained virologic response (SVR) rate in Japan.

Table 2 SVR rate in each prefecture

\begin{tabular}{|c|c|c|c|}
\hline Prefecture no & $\mathbf{n}$ & SVR rate & $\%$ \\
\hline I & 256 & 169 & 66.02 \\
\hline 2 & 250 & 143 & 57.20 \\
\hline 3 & 100 & 56 & 56.00 \\
\hline 4 & 535 & 307 & 57.38 \\
\hline 5 & 112 & 59 & 52.68 \\
\hline 6 & 249 & 135 & 54.22 \\
\hline 7 & 177 & 104 & 58.76 \\
\hline 8 & 62 & 38 & 61.29 \\
\hline 9 & 381 & 253 & 66.40 \\
\hline 10 & 419 & 245 & 58.47 \\
\hline II & 298 & 185 & 62.08 \\
\hline 12 & 220 & 122 & 55.45 \\
\hline 13 & 195 & 113 & 57.95 \\
\hline 14 & 130 & 79 & 60.77 \\
\hline 15 & 12 & 7 & 58.33 \\
\hline 16 & $|4|$ & 70 & 49.65 \\
\hline 17 & 333 & 217 & 65.17 \\
\hline 18 & 326 & 193 & 59.20 \\
\hline 19 & 360 & 225 & 62.50 \\
\hline 20 & 126 & 81 & 64.29 \\
\hline 21 & 894 & 507 & 56.71 \\
\hline 22 & 847 & 491 & 57.97 \\
\hline 23 & 174 & 113 & 64.94 \\
\hline 24 & 19 & 9 & 47.37 \\
\hline 25 & 133 & 74 & 55.64 \\
\hline 26 & 35 & 22 & 62.86 \\
\hline 27 & 427 & 247 & 57.85 \\
\hline 28 & I,39| & 849 & 61.04 \\
\hline 29 & 349 & 210 & 60.17 \\
\hline 30 & 73 & 34 & 46.58 \\
\hline 31 & 57 & 25 & 43.86 \\
\hline 32 & 536 & 324 & 60.45 \\
\hline 33 & 561 & 344 & 61.32 \\
\hline 34 & 895 & 583 & 65.14 \\
\hline 35 & 532 & 308 & 57.89 \\
\hline 36 & 67 & 48 & 71.64 \\
\hline Total & II,672 & 6,989 & 59.88 \\
\hline
\end{tabular}

Abbreviation: SVR, sustained virologic response. these differences can have clinical implications. Masaki et al ${ }^{10}$ previously reported differences in the SVR rates among nine regions in Japan. Although our results are similar, ours is the first study to evaluate prefectural differences in HCV infection treatment using a nationwide database. Prefecture is the unit of local government in Japan, which develops a local medical plan. ${ }^{16}$ Therefore, analysis focusing on prefecture is important to understand regional differences in HCV infection treatment in Japan. Regional differences in treatment and outcomes have also been reported for other diseases, including acute myocardial infarction, ${ }^{17}$ locoregional esophageal cancer, ${ }^{18}$ and preserved cardiac function heart failure. ${ }^{19}$ While regional differences in treatment of various diseases have been reported, investigations focusing on chronic $\mathrm{HCV}$ infection are limited. ${ }^{10,20,21}$ Therefore, the results of this study provide useful information, regarding the possible existence of regional differences in current standard HCV infection treatment.

Table 3 Logistic regression analysis

\begin{tabular}{|c|c|c|}
\hline Variable & Odds ratio $(95 \% \mathrm{Cl})$ & $P$-value \\
\hline Age, years & $0.964(0.959-0.968)$ & $<0.0001$ \\
\hline Sex (male vs female) & $1.376(1.267-1.494)$ & $<0.0001$ \\
\hline $\begin{array}{l}\text { Platelet count } \\
\left(>15 \times 10^{4} / \mu \mathrm{L} \text { vs } \leq 15 \times 10^{4} / \mu \mathrm{L}\right)\end{array}$ & $1.505(1.385-1.636)$ & $<0.0001$ \\
\hline ALT level (>30 IU/L vs $\leq 30 \mathrm{IU} / \mathrm{L})$ & $1.194(1.079-1.320)$ & 0.0006 \\
\hline HCV viral load (high vs low) & $0.321(0.263-0.392)$ & $<0.0001$ \\
\hline Genotype (genotype $2 / 3$ vs I) & $3.847(3.491-4.239)$ & $<0.0001$ \\
\hline $\begin{array}{l}\text { Treatment experience } \\
\text { (retreatment vs initial treatment) }\end{array}$ & $0.69 I(0.63 I-0.756)$ & $<0.0001$ \\
\hline
\end{tabular}

Drug Design, Development and Therapy 2016:10 

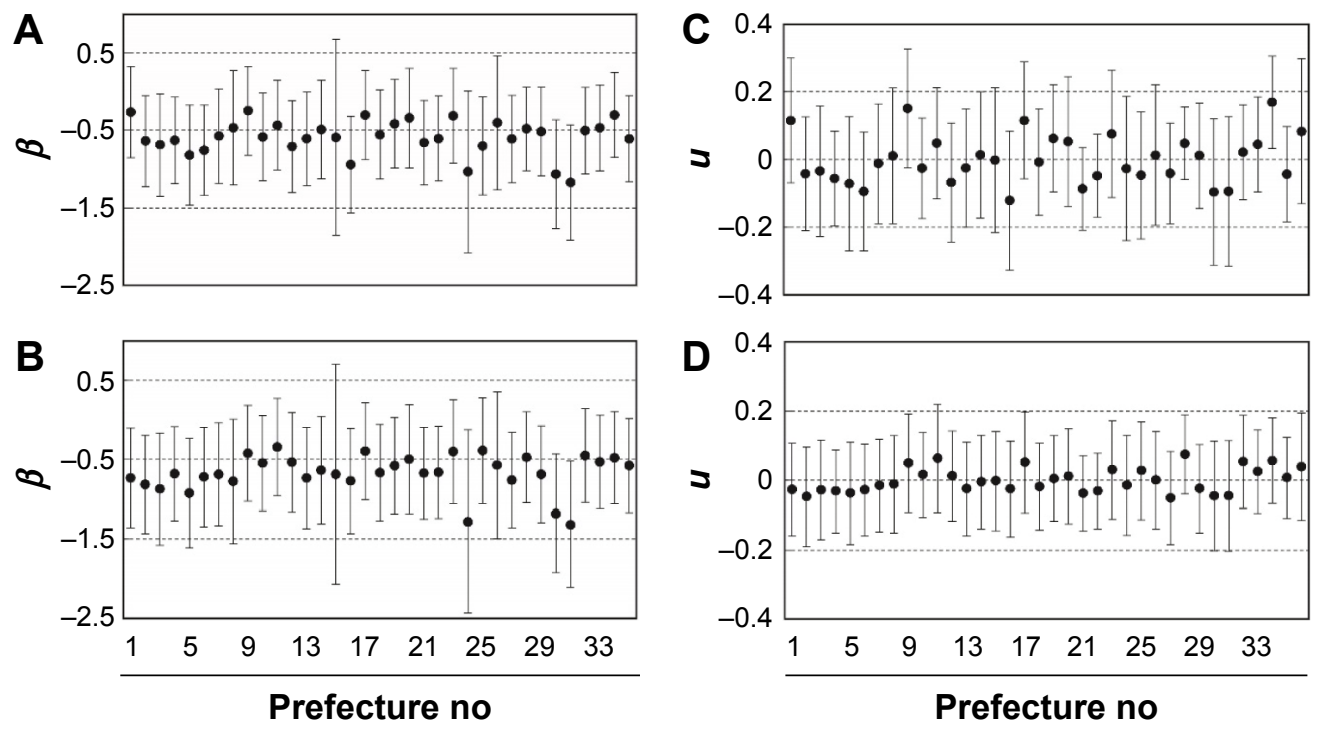

\begin{tabular}{llll}
\hline Fixed-effect & Random-effect & AIC & BIC \\
\hline Prefecture & - & $15,721.68$ & $15,986.82$ \\
Prefecture/confounding variables & - & $13,845.30$ & $14,161.99$ \\
- & Prefecture & $15,716.27$ & $15,719.43$ \\
Confounding variables & Prefecture & $13,830.92$ & $13,845.17$ \\
\hline
\end{tabular}

Figure 2 Parameters of sustained virologic response (SVR) dispersion and quality of model fit.

Notes: (A) Model including prefecture as a fixed effect. (B) Model including prefecture and other confounding variables as fixed effects. (C) Model including prefecture as a random effect. (D) Model including prefecture as a random effect and other confounding variables as fixed effects. $\beta$ is the fixed-effect parameter, and $\boldsymbol{u}$ is the random-effect parameter.

Abbreviations: AIC, akaike information criterion; BIC, bayesian information critreion.

In stepwise logistic regression analysis, age, sex, platelet count, ALT level, HCV viral load, genotype, and treatment experience were selected as confounding variables that could affect the SVR rate of HCV infection treatment with PEG-IFN and RBV. In the analysis using GLMMs, these confounding variables were considered as fixed or random effects. When using data from a nationwide and/or multinational study, regional differences in the clinical characteristics of participants are important. ${ }^{22}$ Hence, the variables used in the statistical models in this study also have important medical implications. Four models were constructed for analysis of regional differences, and the model including SVR rate as a binary response, prefecture as a random effect, and other confounding variables as fixed effects showed the best fit based on the AIC and BIC. This result suggests that the model is appropriate for analysis of regional differences in HCV infection treatment with PEG-IFN and RBV.

However, there are several limitations in this study. The main limitation is the lack of information, regarding the medical resources in each prefecture, as well as each patient's accessibility to such resources. Limited accessibility to medical resources affects the quality of treatment. Historically, few primary care physicians have treated individuals with $\mathrm{HCV}$ infection in rural areas or prisons due to lack of training, which has caused a delay in treatment. ${ }^{20}$ Problems due to lack of access to specialty care services at communitybased health centers have also been reported. ${ }^{23,24}$ Therefore, the medical situations in each prefecture and in each patient should be considered in future studies. Previously, researchers have indicated that the number of specialists in hepatology designated by the Japan Society of Hepatology per 100,000 in nine regions of Japan was not correlated to the SVR rate of these regions. ${ }^{10}$ From this aspect, other factors affecting the difference in SVR rate in each prefecture have to be considered.

The dispersion of the number of registered cases in each prefecture is also important. Seven out of 36 prefectures registered $<100$ cases. Collecting all of the cases treated during the study period is desirable to evaluate regional differences in treatment outcome, but it is impossible to register all cases in daily clinical practice. Although several prefectures registered a small number of cases, the SVR rates in these prefectures ranged from $43.9 \%$ to $71.6 \%$ and were not biased. Therefore, the dispersion may not have affected the results of this study. Although generalizable analysis can be performed using data from large numbers of individuals, the population cannot be separated based on genotypes. The SVR rates and the treatment regimens were 
different among HCV genotypes in clinical settings, and an analysis of each genotype with improved statistical methods is needed in future studies.

\section{Conclusion}

In summary, regional, particularly prefectural, differences may exist in HCV infection treatment with PEG-IFN and RBV in Japan. The statistical model including SVR rate as a binary response, prefecture as a random effect, and other confounding variables as fixed effects is appropriate for analysis of such regional differences. Additional studies considering the medical situations of each patient and recent IFN-free treatments would provide useful information that could contribute to improve and standardize HCV infection treatment. In addition, they could also expand the possibilities for application of the statistical models proposed in this study.

\section{Acknowledgments}

This work was supported by a Grant-in-Aid from the Ministry of Health, Labour and Welfare of Japan (Research on Hepatitis: 2009-2014) and a Grant-in-Aid from the National Center for Global Health and Medicine (27A1301) to NM. The authors wish to thank Ms Mikako Kajio and Ms Asako Horihara for their technical assistance during the data analysis. They would also like to acknowledge the great contributions of the 36 prefectural members and all of the medical staff engaged in the long-term IFN treatment and data collection.

\section{Author contributions}

$\mathrm{KI}, \mathrm{YK}, \mathrm{HY}$ and NM designed the study. KI, YK and NM performed the research and collected the data. KI and YK analysed the data. KI wrote the manuscript. All authors contributed toward data analysis, drafting and revising the paper and agree to be accountable for all aspects of the work.

\section{Disclosure}

The authors report no conflicts of interest in this work.

\section{References}

1. Ghany MG, Strader DB, Thomas DL, Seeff LB; American Association for the Study of Liver Diseases. Diagnosis, management, and treatment of hepatitis C: an update. Hepatology. 2009;49:1335-1374.

2. World Health Organization [webpage on the Internet]. Hepatitis C. Fact Sheet No. 164 July 2015. 2015. Available from: http://www.who.int/ mediacentre/factsheets/fs164/en/. Accessed August 12, 2015.

3. Averhoff FM, Glass N, Holtzman D. Global burden of hepatitis C: considerations for healthcare providers in the United States. Clin Infect Dis. 2012;55(suppl 1):S10-S15.

4. Ghany MG, Nelson DR, Strader DB, Thomas DL, Seeff LB; American Association for Study of Liver Diseases. An update on treatment of genotype 1 chronic hepatitis $\mathrm{C}$ virus infection: 2011 practice guideline by the American Association for the Study of Liver Diseases. Hepatology. 2011; $54: 1433-1444$.
5. Gane EJ, Stedman CA, Hyland RH, et al. Nucleotide polymerase inhibitor sofosbuvir plus ribavirin for hepatitis C. N Engl J Med. 2013; 368:34-44.

6. Lawitz E, Poordad FF, Pang PS, et al. Sofosbuvir and ledipasvir fixeddose combination with and without ribavirin in treatment-naive and previously treated patients with genotype 1 hepatitis $\mathrm{C}$ virus infection (LONESTAR): an open-label, randomised, phase 2 trial. Lancet. 2014; 383:515-523.

7. Mizokami M, Yokosuka O, Takehara T, et al. Ledipasvir and sofosbuvir fixed-dose combination with and without ribavirin for 12 weeks in treatment-naive and previously treated Japanese patients with genotype 1 hepatitis $\mathrm{C}$ : an open-label, randomised, phase 3 trial. Lancet Infect Dis. 2015;15:645-653.

8. Pawlotsky JM. New hepatitis C therapies: the toolbox, strategies, and challenges. Gastroenterology. 2014;146:1176-1192.

9. Negro F, Alberti A. The global health burden of hepatitis $\mathrm{C}$ virus infection. Liver Int. 2011;31(suppl 2):1-3.

10. Masaki N, Yamagiwa Y, Shimbo T, et al; Prefectural Members Contributing to the Japanese Interferon Database. Regional disparities in interferon therapy for chronic hepatitis $C$ in Japan: a nationwide retrospective cohort study. BMC Public Health. 2015;15:566.

11. Gonzalez-Peralta RP, Kelly DA, Haber B, et al; International Pediatric Hepatitis $C$ Therapy Group. Interferon alfa-2b in combination with ribavirin for the treatment of chronic hepatitis $\mathrm{C}$ in children: efficacy, safety, and pharmacokinetics. Hepatology. 2005;42:1010-1018.

12. Hosmer DW Jr, Lemeshow S, Sturdivant RX. Applied Logistic Regression. 3rd ed. Hoboken, NJ: John Wiley \& Sons; 2013.

13. Larsen K, Petersen JH, Budtz-Jørgensen E, Endahl L. Interpreting parameters in the logistic regression model with random effects. Biometrics. 2000;56:909-914.

14. Akaike H. A new look at the statistical model identification. IEEE Trans Automat Contr. 1974;19:716-723.

15. Schwarz G. Estimating the dimension of a model. Ann Stat. 1978; 6:461-464.

16. Ministry of Health, Labor and Welfare of Japan [webpage on the Internet]. Health Policy Publication No. 0330-28. 2012. Available from: http://www.mhlw.go.jp/seisakunitsuite/bunya/kenkou_iryou/ iryou/iryou_keikaku/dl/tsuuchi_iryou_keikaku.pdf. Accessed August 12, 2015.

17. O'Connor GT, Quinton HB, Traven ND, et al. Geographic variation in the treatment of acute myocardial infarction: the Cooperative Cardiovascular Project. JAMA. 1999;281:627-633.

18. Steyerberg EW, Earle CC, Neville BA, Weeks JC. Racial differences in surgical evaluation, treatment, and outcome of locoregional esophageal cancer: a population-based analysis of elderly patients. J Clin Oncol. 2005;23:510-517.

19. Pfeffer MA, Claggett B, Assmann SF, et al. Regional variation in patients and outcomes in the Treatment of Preserved Cardiac Function Heart Failure With an Aldosterone Antagonist (TOPCAT) trial. Circulation. 2015;131:34-42.

20. Spaulding AC, Weinbaum CM, Lau DT, et al. A framework for management of hepatitis C in prisons. Ann Intern Med. 2006;144:762-769.

21. Jou JH, Sulkowski MS, Noviello S, et al. Analysis of site performance in academic-based and community-based centers in the IDEAL Study. J Clin Gastroenterol. 2013;47:e91-e95.

22. Massie BM, Cleland JG, Armstrong PW, et al. Regional differences in the characteristics and treatment of patients participating in an international heart failure trial. J Card Fail. 1998;4:3-8.

23. Cook NL, Hicks LS, O'Malley AJ, Keegan T, Guadagnoli E, Landon BE. Access to specialty care and medical services in community health centers. Health Aff (Millwood). 2007;26:1459-1468.

24. Adashi EY, Geiger HJ, Fine MD. Health care reform and primary care - the growing importance of the community health center. $N$ Engl J Med. 2010;362:2047-2050. 


\section{Publish your work in this journal}

Drug Design, Development and Therapy is an international, peerreviewed open-access journal that spans the spectrum of drug design and development through to clinical applications. Clinical outcomes, patient safety, and programs for the development and effective, safe, and sustained use of medicines are a feature of the journal, which has also been accepted for indexing on PubMed Central. The manuscript management system is completely online and includes a very quick and fair peer-review system, which is all easy to use. Visit http://www.dovepress.com/testimonials.php to read real quotes from published authors.

Submit your manuscript here: http://www.dovepress.com/drug-design-development-and-therapy-journal 